\title{
A Rational Comparison of the Optimal Promoter Edge Decoration of HDT NiMoS vs CoMoS Catalysts
}

\author{
K. Marchand, C. Legens, D. Guillaume and P. Raybaud* \\ Institut français du pétrole, IFP-Lyon, BP 3, Rond point de l'échangeur de Solaize, 69360 Solaize - France \\ e-mail: christelle.legens@ifp.fr - denisjm.guillaume@ifp.fr - pascal.raybaud@ifp.fr \\ *Corresponding author
}

\begin{abstract}
Résumé - Étude comparative de la décoration optimale par le promoteur des phases CoMoS et NiMoS actives en hydrotraitement - Dans le but d'acquérir une meilleure compréhension de la morphologie et la teneur en promoteur de la phase active des catalyseurs d'hydrotraitement dans les conditions de l'hydrotraitement, une étude multi-technique a été entreprise sur une série de catalyseurs $\mathrm{NiMoP}$ avec des ratios Ni/Mo variables. La combinaison de la spectroscopie photoélectronique-X, de la microscopie électronique à transmission, de la modélisation moléculaire $a b$ initio et de tests catalytiques d'hydrogénation du toluène a permis d'aboutir à un modèle morphologique qui a été comparé à une précédente étude menée sur une série analogue promue par le cobalt. Cette étude confirme l'importance de la présence de sites mixtes Ni-Mo sur les bords des cristallites, en particulier sur le bord M-edge pour les réactions d'hydrogénation. Ces résultats permettent d'orienter la mise au point de nouveaux catalyseurs dans le but de maximiser leurs performances.
\end{abstract}

\footnotetext{
Abstract - A Rational Comparison of the Optimal Promoter Edge Decoration of HDT NiMoS vs CoMoS Catalysts - In order to gain a better understanding of the morphology and promoter edge content of the active phase of industrial HDT NiMoP catalysts in working conditions, a multi-technique study has been undertaken on a series of NiMoP catalysts with various Ni/Mo ratios. The combination of X-ray Photoelectron Spectroscopy (XPS), Transition Electron Microscopy (TEM), Density Functional Theory (DFT) modeling and catalytic testing (toluene hydrogenation) provided data to build a morphological model of NiMoS nanocrystallites. A parallel has been established with their CoMoS counterparts obtained in our previous work in order to emphasize differences arising from the promoter atom. This study confirms the importance of the presence of mixed Ni-Mo sites on the edges of the NiMoS nanocrystallites, and especially on the M-edge for reactions involving hydrogenation. These results provide new guidelines for future and ever more active catalysts.
} 


\section{INTRODUCTION}

The production of ever cleaner fuels with ultra low sulfur content requires a continuous improvement of the catalysts used by the refining industry. Sulfides catalysts such as $\gamma$-alumina supported $\mathrm{Co}(\mathrm{Ni}) \mathrm{MoS}$ have been widely used in hydrotreatment processes for the last six decades. However, until the early 80 s, very little information was available about the structures of the active phase of industrial HDT catalysts in working conditions. They are now better characterized and understood. The active phase consists of $\mathrm{Co}(\mathrm{Ni})$ promoted $\mathrm{MoS}_{2}$ nanocrystallites. Promotions/decorations and sulfidations of those catalysts may be characterized by X-ray Photoelectron Spectroscopy (XPS). This technique is also appropriate to identify the electronic state of Co species [1-4] and Ni species [5-7] in the active phase and to quantify them $[8,9]$. More recently, Density Functional Theory (DFT) has also appeared as a very efficient method to bring new insights on the local structure and electronic properties of the active phase of HDT catalysts $[10,11]$. Moreover, in line with the geometrical model earlier proposed by Kasztelan et al. [12], the stable morphologies of the active CoMoS and NiMoS phases in reaction conditions have been solved by DFT calculations [13]. For instance, Schweiger [14] et al. put forward two distinct behaviors at the metallic-edge and sulfur-edge with respect to the promoter: they found that $\mathrm{Co}$ is more stable in substitution at the S-edge than at the Mo-edge due to a smaller edge energy at the S-edge, which is also supported by other DFT simulations [15] and STM experiments on gold supported CoMoS [16]. These calculations have been successfully confronted to experimental results on CoMo catalysts in a previous study [8]: the decomposition of the XPS spectral envelope was used to quantify the amount of CoMoS phase, determine the promoter-to-molybdenum ratio in the nanocrystallites and normalize the catalytic activity in toluene hydrogenation per edge CoMoS site. It was thus found that the optimal promoter-to-molybdenum atomic ratio in the nanocrystallite (decoration ratio) corresponded to $(\mathrm{Co} / \mathrm{Mo})_{\mathrm{CoMoS}}=0.3$, a ratio for which a total decoration of the S-edge is obtained whereas the substitution of the M-edge corresponds to $50 \%$. In the present work, we extended that study to NiMo catalysts, exploring the characteristics of the NiMoS active phase by a multitechnique approach combining X-ray Photoelectron Spectroscopy (XPS), Transmission Electron Microscopy (TEM), catalytic tests and Density Functional Theory (DFT) calculations. Our goal is here again to gain a better understanding of the promoter decoration at the edges of the $\mathrm{MoS}_{2}$ crystallites, taking into account the crystallites morphology effects and to focus on the differences arising from the use of different promoter atoms. We finally make a proposal deduced from these techniques for the most coherent model of morphology and active sites of the NiMoS phase and thus discuss it with respect to the $\mathrm{CoMoS}$ phase model recently proposed on the same bases.

\section{EXPERIMENTAL METHODS}

\subsection{Preparation of the Catalysts}

The oxidic precursors were prepared by incipient wetness impregnation of $\gamma$-alumina extrudates (from Axens) with impregnation solutions containing the appropriate amount of metal to be deposited. The impregnated extrudates were then placed in water-saturated atmosphere for at least $3 \mathrm{~h}$ and then dried at $120^{\circ} \mathrm{C}$ overnight. Finally the solids were calcined under air at $500^{\circ} \mathrm{C}$ for $2 \mathrm{~h}$.

The NiMoP catalysts with various $\mathrm{Ni} / \mathrm{Mo}$ ratio were prepared with impregnation solutions containing Strandbergtype heteropolycompound $\mathrm{Ni}_{x} \mathrm{P}_{2} \mathrm{Mo}_{5} \mathrm{O}_{23}$ [17]. A large excess of phosphoric acid, corresponding to $1.9 \mathrm{wt} \% \mathrm{P}$ loading, was necessary to dissolve the molybdenum and nickel precursors. The Mo loading was of $12.7 \mathrm{wt} \%$ as Mo, the concentration of $\mathrm{Ni}$ was adjusted to obtain various nickel-to-molybdenum molar ratios. These catalysts will be referred to as $\mathrm{Ni}_{x} \mathrm{MoP}$, where $x$ represents the $\mathrm{Ni} / \mathrm{Mo}$ atomic ratio. The Ni loadings correspond respectively to $0.8,1.6,2.4,3.1,3.9,4.6$ and $5.4 \mathrm{wt} \% \mathrm{Ni}$ for respectively $0.1,0.2,0.3,0.4,0.5,0.6$ and 0.7 ratios. Definitions and compositions of the prepared catalysts are listed in Table 1 .

TABLE 1

Definitions and compositions of NiMoP catalysts

\begin{tabular}{|c|c|c|c|c|c|}
\hline Catalyst & Ni loading (wt\%) & Mo loading (wt $\%$ ) & P loading (wt $\%$ ) & $\begin{array}{c}\text { (Theoretical } \mathrm{Ni} / \mathrm{Mo} \\
\text { ratio }(\mathrm{mol} / \mathrm{mol})\end{array}$ & $\begin{array}{c}\text { Experimental Ni/Mo ratio } \\
\text { by XRF }(\mathrm{mol} / \mathrm{mol})\end{array}$ \\
\hline $\mathrm{Ni}_{0.1} \mathrm{MoP}$ & 0.8 & 12.8 & 1.8 & 0.10 & 0.10 \\
\hline $\mathrm{Ni}_{0.2} \mathrm{MoP}$ & 1.6 & 12.9 & 1.9 & 0.20 & 0.20 \\
\hline $\mathrm{Ni}_{0.3} \mathrm{MoP}$ & 2.4 & 13.0 & 1.9 & 0.30 & 0.30 \\
\hline $\mathrm{Ni}_{0.4} \mathrm{MoP}$ & 3.1 & 12.6 & 1.8 & 0.40 & 0.40 \\
\hline $\mathrm{Ni}_{0.5} \mathrm{MoP}$ & 3.9 & 12.7 & 2.0 & 0.50 & 0.50 \\
\hline $\mathrm{Ni}_{0.6} \mathrm{MoP}$ & 4.6 & 12.5 & 1.9 & 0.60 & 0.61 \\
\hline $\mathrm{Ni}_{0.7} \mathrm{MoP}$ & 5.4 & 12.5 & 2.0 & 0.70 & 0.71 \\
\hline
\end{tabular}




\subsection{Sulfidation Conditions}

The oxide precursors were sulfided at atmospheric pressure under a $\mathrm{H}_{2} \mathrm{~S} / \mathrm{H}_{2}$ mixture with a $\mathrm{p}\left(\mathrm{H}_{2} \mathrm{~S}\right) / \mathrm{p}\left(\mathrm{H}_{2}\right)$ ratio about 0.17 and a gas flow of $2 \mathrm{~L} / \mathrm{h} / \mathrm{g}$ of catalyst. The samples were heated under the sulfiding mixture at a rate of $5^{\circ} \mathrm{C} / \mathrm{min}$ up to $400^{\circ} \mathrm{C}$ and maintained at this temperature for $2 \mathrm{~h}$. They were then cooled down to room temperature at a rate of $20^{\circ} \mathrm{C} / \mathrm{min}$ also under the reactive mixture. The sulfided catalysts were transferred into glass vials under vacuum in order to avoid any contact with air.

\subsection{TEM Analysis}

The sulfided samples were analyzed by TEM to determine the average lengths and stackings of the $\mathrm{MoS}_{2}$ nanocrystallites by counting at least 350 particles. The extrudates were crushed into a fine powder, a small amount of which being ultra sonically diluted in ethanol. Two drops of this solution were deposited on a carbon-coated $\mathrm{Cu}$ grid and the solvent was evaporated under infrared light. TEM images were taken using a $200 \mathrm{kV}$ JEOL-2010 transmission electron microscope equipped with a digital camera.

\subsection{XPS Analysis}

The XPS sampling of the sulfided catalysts was performed in a glove box under argon atmosphere, with controlled oxygen and water level (less than $20 \mathrm{ppm}$ ) in order to avoid their partial reoxidation. The samples were crushed and pressed onto an indium foil that was attached to the sample holder via a double side carbon tape. The sample holder was then moved directly to the introduction chamber of the XPS spectrometer, thanks to the special connection of the glove box to the XPS spectrometer. The XPS spectra were recorded on a Kratos Axis Ultra instrument with Al monochromator source $(1486.6 \mathrm{eV})$ and a hemi-spherical analyzer operating at fixed pass energy of $40 \mathrm{eV}$. The measurements were made at $293 \mathrm{~K}$ in steps of $0.05 \mathrm{eV}$ for nickel, $0.1 \mathrm{eV}$ for sulfur and $0.1 \mathrm{eV}$ for molybdenum, and at a pressure lower than $1 \times 10^{-9} \mathrm{~Pa}$ in the sample analysis chamber. Binding energies (BE) of the various elements have been referenced to the $\mathrm{C} 1 \mathrm{~s}$ level of the contamination carbon at $284.6 \mathrm{eV}$ (the $\mathrm{Al} 2 \mathrm{p}$ is found at $74.7 \mathrm{eV}$ ). The curves were integrated applying a Shirley type baseline. The collected spectra were analyzed by using CasaXPS software, Version 2.0.71. The decomposition of the S 2p, Mo 3d and Ni 2p XPS spectra were performed using the appropriate oxide and sulfided references as supported monometallic catalysts and led us to propose a protocol to quantify inter alia the NiMoS phase, as had already been obtained previously for CoMoS type phase $[3,8]$.

For $\mathrm{Ni}$, we found 3 different species on the catalysts referred to $\mathrm{Ni}(\mathrm{II})$ oxide as present on the oxide mono metallic catalyst with a main binding energy position at $856.0 \pm 0.1 \mathrm{eV}[18]$. The same reference after sulfidation showed another contribution named $\mathrm{Ni}$ sulfide $\left(\mathrm{NiS}_{\mathrm{x}}\right)$ (as it was difficult to define the exact stoechiometry) with the main $\mathrm{Ni} 2 \mathrm{p}_{3 / 2}$ position at $853.1 \pm 0.1 \mathrm{eV}$. And after sulfidation of the bimetallic catalyst, a third contribution has to be integrated to fit correctly the spectrum (Fig. 1 and 2). This contribution, associated to the formation of the NiMoS phase, is mainly positioned at $854.0 \pm 0.1 \mathrm{eV}$ in agreement with others papers [19, 20].

The effective atomic concentration [i] of the atom i was obtained from the measurement of the corresponding total peak area $\mathrm{Ai}$ and the use of appropriate sensitivity factor $\mathrm{Si}$

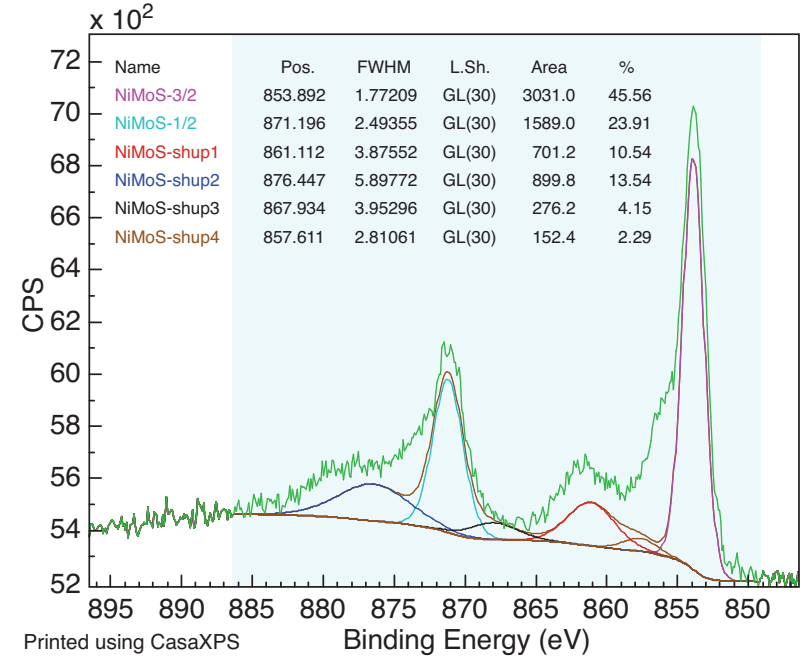

Figure 1

Experimental decomposition of the NiMoS phase.

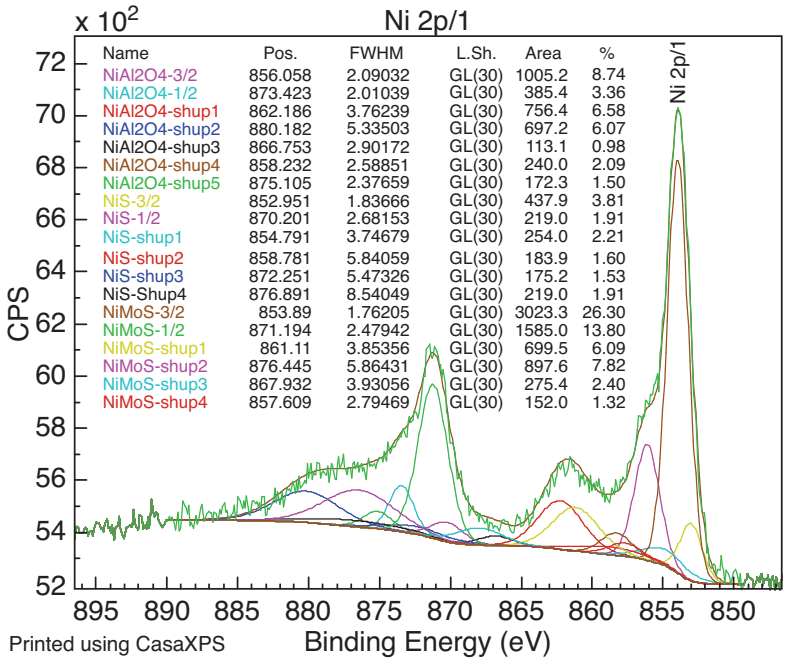

Figure 2

Experimental decomposition of all the Ni species. 
furnished by the constructor. To approach the effective atomic surface concentrations, all the atoms (except the contamination carbon) detected on the surface were taken into account (Eq. 1).

$$
[\mathrm{i}]=\frac{\frac{\mathrm{A} i}{\mathrm{~S} i}}{\sum_{i=1}^{i=n}\left(\frac{\mathrm{A} i}{\mathrm{Si}}\right)}
$$

For one atom, the signal obtained can be decomposed into different contributions relative to various chemical species. The calculation of the respective contribution of each peak area will lead to the knowledge of the relative proportion of each chemical form for a given atom. For example in the case of $\mathrm{Ni}$ atoms detected as $\mathrm{Ni}(\mathrm{II})$ oxide, NiMoS and Ni sulfide $\left(\mathrm{NiS}_{x}\right)$, the relative amount in $\mathrm{NiMoS}$ phase is given Equation (2).

$$
\% \mathrm{NiMoS}=\frac{A_{\mathrm{NiMoS}}}{A_{\mathrm{NiMoS}}+A_{\mathrm{Ni}(\mathrm{II})}+A_{\mathrm{NiS} x}} \times 100
$$

with $A_{\mathrm{NiMoS}}, A_{\mathrm{Ni}(\mathrm{II})}$ and $A_{\mathrm{NiS} x}$ the experimental XPS area of respectively NiMoS, $\mathrm{Ni}$ (II) oxide and $\mathrm{Ni}$ sulfide species.

We may then deduce the effective amount of NiMoS phase noted [NiMoS] by multiplying the relative value with the total $\mathrm{Ni}$ content [Ni] measured by XPS (Eq. 3).

$$
[\mathrm{NiMoS}]=\% \mathrm{NiMoS} \times[\mathrm{Ni}]
$$

Two samples have been analyzed for each catalyst and the data presented in this paper correspond to the average values of both analysis. Figure 1 is the illustration of the NiMoS phase signal experimentally found, after deduction of the monometallic oxide and sulfide nickel. Figure 2 shows the experimental XPS spectrum after complete decomposition into the three species mentioned above.

\subsection{Catalytic Measurements}

The catalytic tests performed in this study were carried out in a fixed bed-high pressure flow microreactor under the following conditions: $4 \mathrm{~cm}^{3}$ of length-selected extrudates (2-4 mm), a total pressure of 60 bar corresponding to $\mathrm{p}\left(\mathrm{H}_{2} \mathrm{~S}\right)$ $=2.15$ bar, $\mathrm{p}\left(\mathrm{H}_{2}\right)=36.9$ bar, reaction temperature of $350^{\circ} \mathrm{C}$, Liquid Hourly Space Velocity (LHSV) of $2 \mathrm{~h}^{-1}$, hydrogen-tofeed ratio of $450 \mathrm{~L} / \mathrm{L}$. The feed consists of a dimethyldisulfide $(5.9 \mathrm{wt} \%)$ and toluene (20 wt $\%$ ) mixture in cyclohexane. After the unit was pressure-tested at room temperature, the temperature was increased at $3^{\circ} \mathrm{C} / \mathrm{min}$ to $350^{\circ} \mathrm{C}$. Steady-state conversion was measured after $2 \mathrm{~h}$ on stream. Reaction products were analyzed by on line gas chromatography. The activity in toluene-hydrogenation was expressed considering a first-order reaction.

\subsection{DFT Calculations for the Morphology Determination}

The DFT results used in this work are presented in details in the companion paper by Krebs et al. published in this issue [21] as well as in a previous paper [22]. Total energy calculations are based on the plane wave density functional theory within the generalized gradient approximation [23, 24] and periodic boundary conditions. For that, we used the Vienna $a b$ initio simulation package to solve the Kohn-Sham equations within the Projected Augmented Wave (PAW) formalism [25]. All details on the methodology and approximations (cut-off energy, convergence criteria, cell's size) are reported in [22]. The main insights useful for the present work and taken from these previous DFT calculations are the determination of the Gibbs-Curie-Wulff morphologies of $\mathrm{Co}(\mathrm{Ni}) \mathrm{MoS}$ nano-crystallites as a function of HDT reactions conditions and promoter content at the edges.

\section{RESULTS}

\subsection{Quantification of the NiMoS and MoS2 Phases Using XPS and XRF}

The Mo 3d spectra of sulfided catalysts were decomposed according to the methods described in [8,3]. Three different oxidation degrees of molybdenum were found: VI (232.1 eV), V (230.1 eV), IV (228.7 eV); they were respectively attributed to the oxide, oxisulfide and sulfide phases. The proportions of each phase have been reported as a function of the experimental nickel-to-molybdenum molar ratio in the catalyst (XRF) in Figure 3. As may be seen from that figure, the different amounts of nickel do not influence the sulfurability of molybdenum: about $70 \%$ of the introduced molybdenum are sulfided into $\mathrm{MoS}_{2}$ whereas about $10 \%$ are still under their oxide form and $20 \%$ are defined as $\mathrm{MoO}_{x} \mathrm{~S}_{y}$ at an intermediate oxidation/sulfidation state. A similar trend was found on cobalt catalysts in previous studies $[8,9]$.

Decompositions of $\mathrm{Ni} 2 \mathrm{p}$ spectra of sulfided catalysts were carried out as described in the experimental section. In the case of the nickel species, since the nickel contents deposited on alumina during the preparation of catalysts vary, it is easier in the first place to follow the evolution of the contents of the different nickel species expressed as a relative percentage. Figure 4 depicts the evolution of the relative contents of the nickel species, $\mathrm{Ni}$ (II), $\mathrm{Ni}$ sulfide and the mixed NiMoS phase, as a function of the experimental nickel-to-molybdenum molar ratio in the catalysts (XRF).

As expected, the variation of the experimental nickel-tomolybdenum molar ratio in the catalysts (denoted (NiMo) $\mathrm{XRF}$ for the sake of clarity) clearly influences the nickel species present at the surface of the sulfided catalysts.

For $(\mathrm{Ni} / \mathrm{Mo})_{\mathrm{XRF}}<0.3$, the results show a clear increase of the proportion of the NiMoS phase at the expense of the 


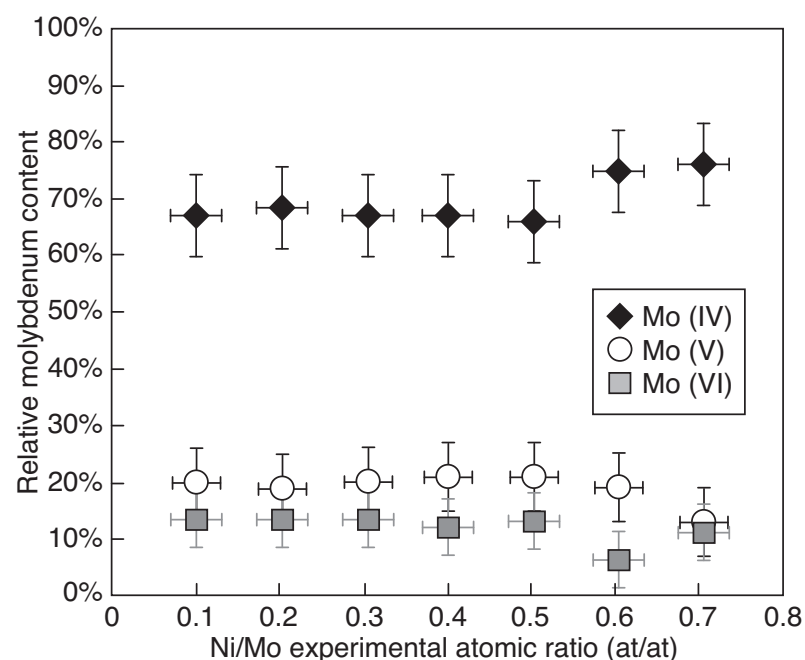

Figure 3

Molybdenum speciation as a function of the experimental nickel-to-molybdenum molar ratio in the catalyst.

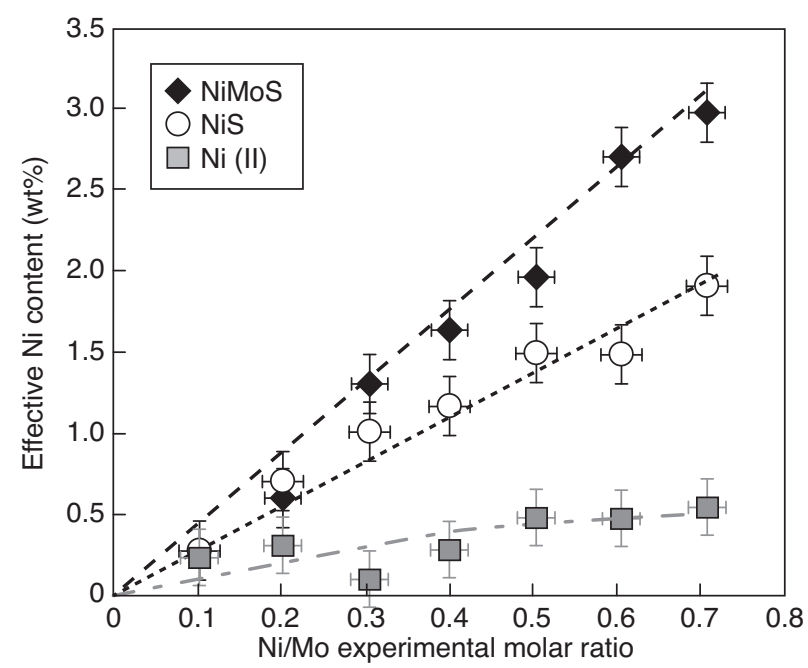

Figure 5

Evolution of the effective content of the nickel species to the molar $(\mathrm{Ni} / \mathrm{Mo})_{\mathrm{XRF}}$ ratio for the sulfided catalysts.

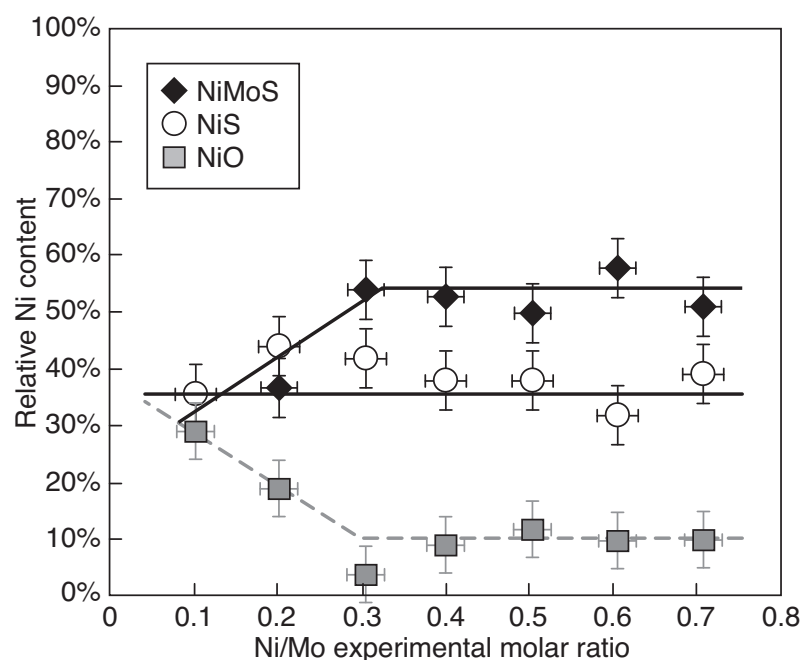

Figure 4

Nickel speciation as a function of $(\mathrm{Ni} / \mathrm{Mo})_{\mathrm{XRF}}$ experimental molar ratio in the catalysts.

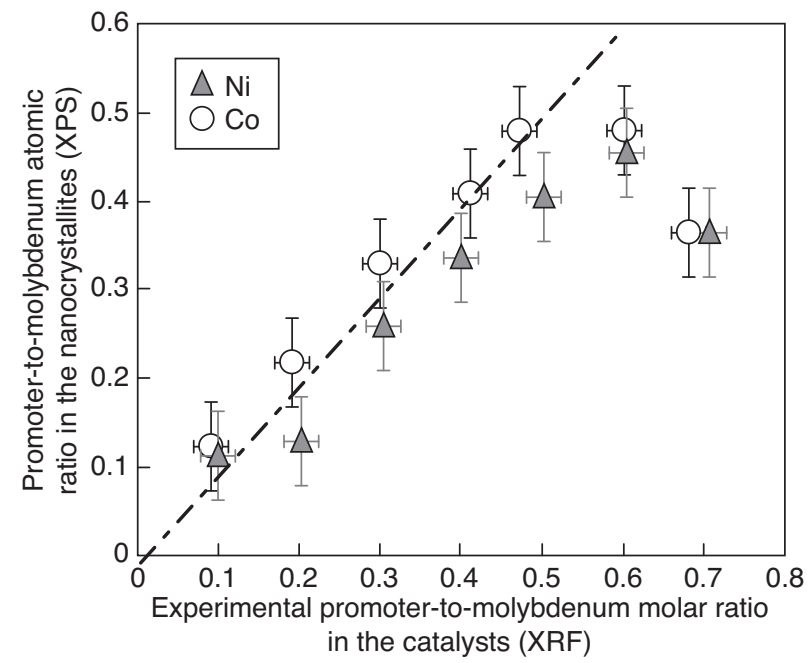

Figure 6

Evolution of the promoter-to-molybdenum atomic ratio in the $\mathrm{MoS}_{2}$ nanocrystallites as a function of the experimental promoter-to-molybdenum molar ratio (quantified by XPS), the promoter being either $\mathrm{Ni}$ or $\mathrm{Co}$.
Ni(II) oxide phase, which means that the additional nickel added clearly helps to form more NiMoS phase. The proportion of residual $\mathrm{Ni}$ (II) oxide accordingly decreases while the amount of sulfide phase remains constant around $35 \%$.

For $(\mathrm{Ni} / \mathrm{Mo})_{\mathrm{XRF}}>0.3$, the proportions of the nickel engaged in the mixed NiMoS phase are steady around $55 \%$. The proportions of residual $\mathrm{Ni}$ oxides and sulfides do not vary anymore and are respectively of $10 \%$ and $35 \%$. These trends are quite different from those previously observed on CoMo catalysts $[8,9]$. Indeed, on those catalysts the amount of CoMoS phase formed is stable and around $60 \%$ for $\mathrm{Co} / \mathrm{Mo}<0.5$ and the proportion of Co inserted in the mixed phase decreases as a function of $\mathrm{Co} / \mathrm{Mo}$ for higher $\mathrm{Co} / \mathrm{Mo}$ ratios.

Figure 5 represents the evolution of the effective contents of the nickel species, expressed in weight percent, as a function of $(\mathrm{Ni} / \mathrm{Mo})_{\mathrm{XRF}}$. These results confirm the trends observed for the evolution of the relative contents for each nickel species: for $(\mathrm{NiMo})_{\mathrm{XRF}} \leq 0.6$, the quantity of NiMoS phase formed during sulfidation increases as a linear function of the quantity of nickel introduced in the catalyst. So do the proportions of nickel introduced in the nickel sulfide phase, and to a lesser extent in the nickel oxide phase. The higher 
the nickel content is, the more mixed NiMoS phase is formed. This trend is somewhat different from what had been observed in our previous study $[8,9]$ since the maximum amount of $\mathrm{CoMoS}$ phase had been obtained for $\mathrm{Co} / \mathrm{Mo}=0.5$ : an increase in the cobalt content led to an increase in the proportion of cobalt sulfide at the expense of the CoMoS phase. For $(\mathrm{Ni} / \mathrm{Mo})_{\mathrm{XRF}}=0.7$, the amount of NiMoS phase is similar to the amount obtained for $(\mathrm{Ni} / \mathrm{Mo})_{\mathrm{XRF}}=0.6$ which is explained by a higher content of $\mathrm{NiS}$ than could be expected from experiments at lower $(\mathrm{Ni} / \mathrm{Mo})_{\mathrm{XRF}}$.

The nickel-to-molybdenum atomic ratios in the NiMoS nanocrystallites, denoted (Ni/Mo) $)_{\mathrm{NiMoS}}$ were calculated from the XPS $\mathrm{MoS}_{2}$ and NiMoS (resp. CoMoS) quantification results. They are reported in Figure 6 together with results obtained from our previous study on their CoMo catalysts counterparts [8]. A similar trend is observed, independently of the promoter atom: the variation of $(\mathrm{Ni} / \mathrm{Mo})_{\mathrm{NiMoS}}$ as a function of $(\mathrm{Ni} / \mathrm{Mo})_{\mathrm{XRF}}$ has the shape of a volcano curve. Considering the experimental error, the maximum corresponds to a promoter-to-molybdenum ratio in the nanocrystallites of about $0.45-0.50$ and, it is in both cases obtained for an experimental promoter-to-molybdenum ratio superior to 0.50 and inferior to 0.60 . (Ni/Mo) $)_{\mathrm{NiMoS}}$ is first similar to $(\mathrm{Ni} / \mathrm{Mo})_{\mathrm{XRF}}$ in the catalyst and, after this maximum has been reached, further introduction of promoter does not contribute anymore to the decoration of $\mathrm{MoS}_{2}$ nanocrystallites but increases the amount of NiS phase (Fig. 5).

\subsection{TEM Results}

All sulfided catalysts were analyzed by TEM in order to determine the morphology of the sulfide phase. The results obtained are very similar to those already published [8] for CoMo catalysts: whatever the (Ni/Mo) XRF ratio, the $\mathrm{MoS}_{2}$ nanocrystallites have approximately the same length, around $3.2 \pm 0.3 \mathrm{~nm}$ and an average stacking of 2 slabs.

\subsection{Catalytic Results}

Catalysts have been tested in toluene hydrogenation. Results are reported in Figure 7. The hydrogenation constant expressed in mole of toluene converted per mole of molybdenum and per hour was plotted as a function of the effective weight of promoter content in nickel incorporated in the mixed phase as obtained by XPS. It is first increasing linearly with the amount of $\mathrm{Ni}$ in the NiMoS phase and then, it remains constant.

\section{DISCUSSION}

\subsection{NiMo vs CoMo Catalysts: Optimal Morphologies and Edges Decorations}

In the same spirit as the geometrical model earlier proposed by S. Kasztelan et al. [12], for a given slab length, we define

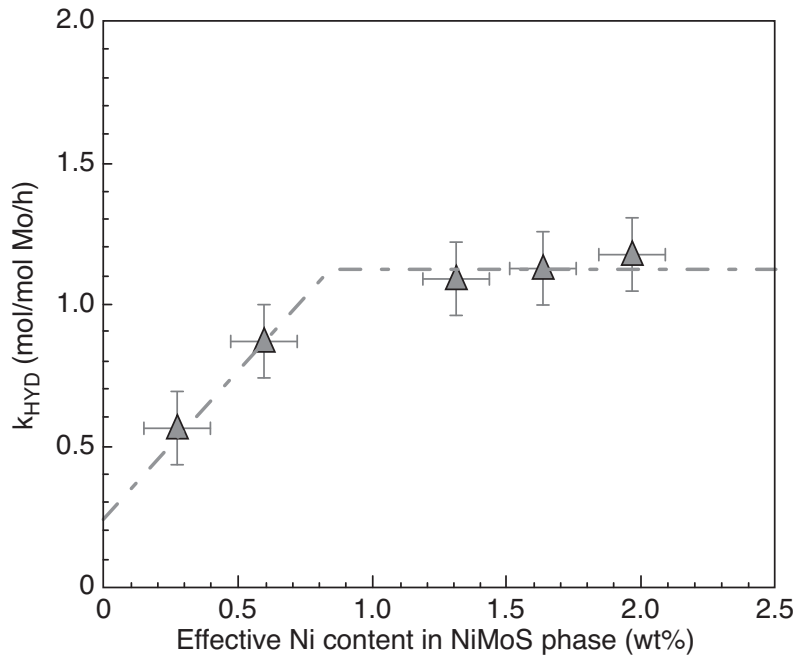

Figure 7

Toluene hydrogenation activity as a function of the effective $\mathrm{Ni}$ weight included in the NiMoS phase.

the morphology of the NiMoS crystallite by two geometrical parameters: $n_{M}$ and $n_{S}$, which respectively stand for the number of atoms on the M-edge and on the S-edge.

From DFT modeling [21, 22], it is known that the NiMoS crystallites exhibit a deformed hexagon-like two-dimensional morphology with a proportion of M-edge of about $0.6-0.65$ in HDT conditions (Fig. 8), which provides us with Equation (4).

$$
0.60 \leq \frac{n_{M}}{n_{M}+n_{S}} \leq 0.65
$$

From TEM results, it is known that the average slab length is around $3.2 \mathrm{~nm}$, leading to Equation (5).

$$
d(M o-M o) \times\left(n_{M}+n_{S}\right)=3.2 \mathrm{~nm}
$$

with $d(\mathrm{Mo}-\mathrm{Mo}) \approx 0.32 \mathrm{~nm}$, according to EXAFS experiments [26].

Combining Equations (4) and (5) leads to $n_{M}=6$ and $n_{S}=4$, as the best compromise between DFT particle morphologies and TEM particle sizes.

It may be relevant to combine these theoretical results with XPS and TEM results to confirm the morphology and provide new insights about atomistic decoration of the nanocrytallites.

The global promoter-to-molybdenum experimental ratios determined by XRF have been reported in Table 2 for both promoters along with the promoter-to-molybdenum decoration ratio in the nanocrystallites determined by XPS. In both cases, the promoter-to-molybdenum atomic ratios in the nanocrystallites do not exceed 0.5 , which is in agreement 


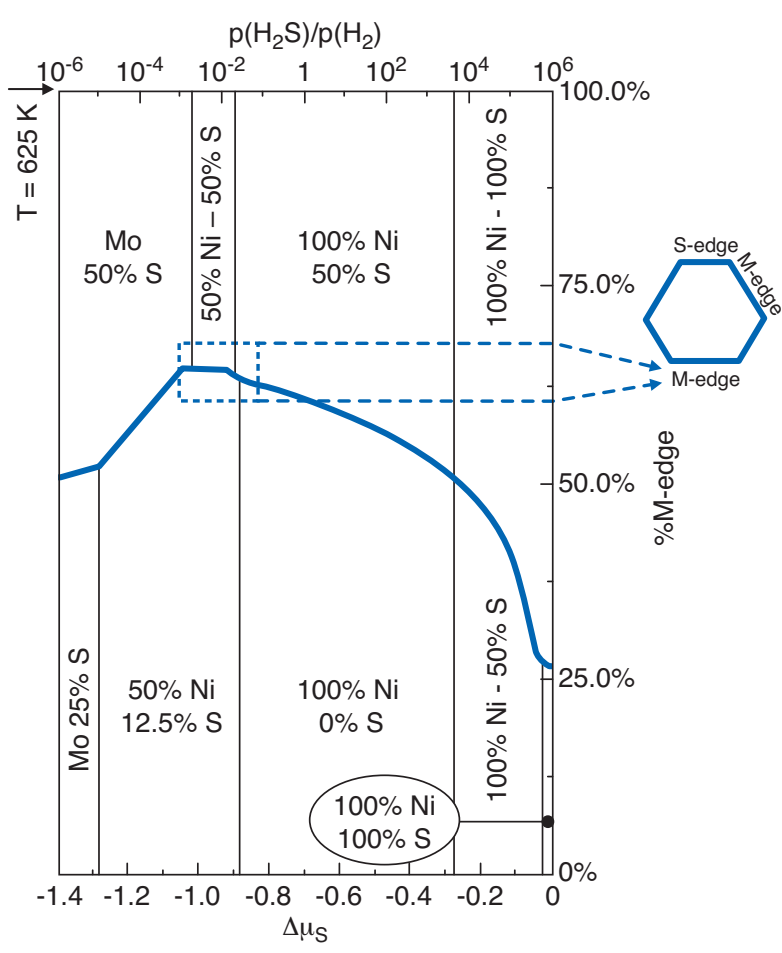

Figure 8

Morphology diagrams for the NiMoS nano-crystallites as a function of $\Delta \mu_{\mathrm{S}}$ and $\mathrm{p}\left(\mathrm{H}_{2} \mathrm{~S}\right) / \mathrm{p}\left(\mathrm{H}_{2}\right)$ at $T=625 \mathrm{~K}$ after reference [22]. The proportion (percentage) of M-edge is given by the blue broken line. The S-edge compositions are reported above the blue line, and the M-edge compositions are below this line. The doted square emphasizes the range of the usual HDS conditions, corresponding to the deformed hexagon-like morphology represented in the inset.

with nanocrystallites morphologies obtained by DFT [21, 22]. The optimum obtained is the same for both promoters. A further increase in promoter loading only results in a decrease in the decoration ratio. This trend is consistent with results obtained for CoMoP catalysts, as mentioned in Table 2.

If we combine these XPS results with TEM evaluation of mean crystallites lengths close to $3.2 \mathrm{~nm}$, it is possible, to

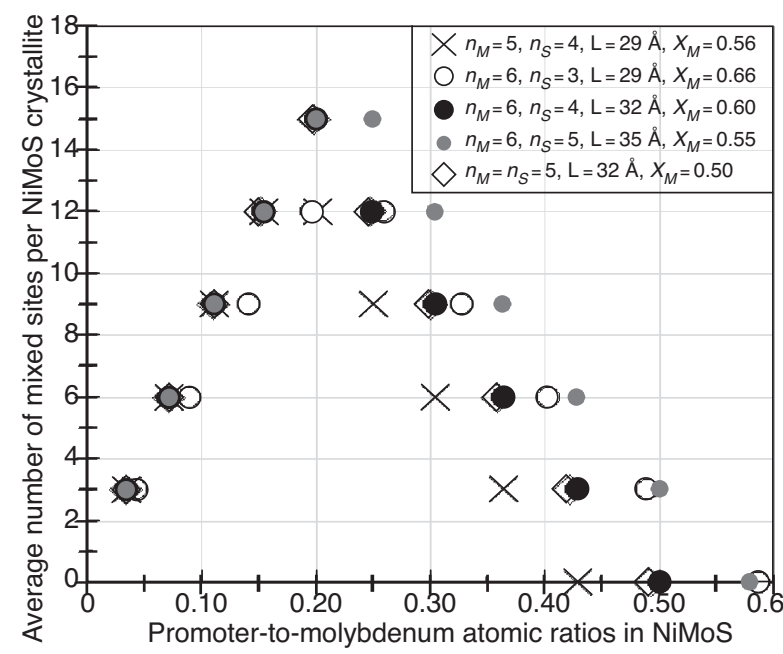

Figure 9

Evolution of the average number of mixed sites per crystallite as a function of the atomic promoter to molybdenum ratio in the nanocrystallites.

propose several geometric models of for NiMoS nanocrystallites. These geometric models are listed in Table 3; the number of mixed sites obtained for each model as a function of the promoter-to-molybdenum atomic ratio in the NiMoS phase is plotted for all models in Figure 9. The number of mixed Ni-Mo sites is determined from general rules derived from DFT results $[21,22]$, which may be shortly summarized for this purpose by:

- a mixed Ni-Mo edge site corresponds to an intermediate sulfur metal-bond energy which value is therefore comprised between the energy of a Ni edge site and a non promoted Mo-edge site;

- $\mathrm{Ni}$ atom prefer to be located on the M-edge than on the S-edge (whereas it is the reverse for Co);

- NiNiMoMo pairing is more stable than NiMoNiMo pairing on the $\mathrm{M}$ edge (whereas CoCoMoMo and CoMoCoMo pairings are close in energy).

TABLE 2

Average promoter to molybdenum molar (XRF) and atomic (XPS) ratios in the catalysts and in the nanocrystallites respectively

\begin{tabular}{c|c|c|c}
\hline $\begin{array}{c}\text { Co/Mo experimental ratio } \\
\text { (mol/mol) [8] }\end{array}$ & $\begin{array}{c}\text { Co/Mo atomic ratio } \\
\text { in the } \mathrm{MoS}_{2} \text { nanocrystallites } \\
\text { from XPS results (at/at) [8] }\end{array}$ & $\begin{array}{c}\text { Ni/Mo experimental ratio } \\
\text { from XRF results (mol/mol) }\end{array}$ & $\begin{array}{c}\text { Ni/Mo atomic ratio } \\
\text { in the MoS } \text { Snocrystallites }_{2} \\
\text { from XPS results (at/at) }\end{array}$ \\
\hline 0.09 & 0.10 & 0.10 & 0.11 \\
0.19 & 0.21 & 0.20 & 0.13 \\
0.30 & 0.30 & 0.30 & 0.26 \\
0.41 & 0.38 & 0.40 & 0.34 \\
0.47 & 0.45 & 0.50 & 0.41 \\
0.60 & 0.47 & $\mathbf{0 . 6 1}$ & $\mathbf{0 . 4 6}$ \\
\hline
\end{tabular}


XPS measurements indicated that the highest promoter-tomolybdenum atomic ratio in the NiMoS crystallites was 0.47 and this is compatible with two geometric models obeying this criterion: either a hexagonal model $n_{M}=n_{S}=5$ or a slightly deformed hexagon model with $n_{M}=6$ and $n_{S}=4$. Hence, It is hard to make a choice without the help of DFT modeling. Indeed, both models fit according to TEM and XPS and the only criterion in favor of the truncated triangle model it conditions (Tab.3).

\subsection{Impact of the Promoter-to-molybdenum Atomic Ratio in the Nanocrystallites on Toluene Hydrogenation Performances}

It is possible to normalize the activity in toluene hydrogenation by the mixed phase content, given by XPS results. These normalized activities have been plotted as a function of the promoter-to-molybdenum atomic ratio in the crystallites for both CoMo (Fig. 10) and NiMo (Fig. 11). It is striking to observe that for both catalysts two regimes exist.
For CoMo catalysts the activity normalized per cobalt introduced in CoMoS phase is first quasi constant up to $(\mathrm{Co} / \mathrm{Mo})_{\mathrm{CoMoS}}<0.2$ and, then, it decreases with increasing saturation of CoMoS edges; this trend has been rationalized by the disappearance of mixed Co-Mo sites on the edges of the crystallites [9]. By using a hexagonal model with $n_{M}=n_{S}$ $=5$, and calculating the S-edge (Fig. 12), M-edge (Fig. 12) and total (Fig. 14) average numbers of mixed Co-Mo sites per crystallites, it is possible to deepen one's understanding of these results. When increasing the decoration ratio $(\mathrm{Co} / \mathrm{Mo})_{\mathrm{CoMoS}}$ from 0 to 0.2 , Co atoms may only decorate $\mathrm{S}$ edge sites. Crystallites with fully decorated S-edges coexist with non-decorated $\mathrm{MoS}_{2}$ crystallite. Hence, the number of Co inserted in the CoMoS phase increases more rapidly than the number of mixed Co-Mo sites $\mathrm{Co}$, which is the reason why the activity does not increase with $(\mathrm{Co} / \mathrm{Mo})_{\mathrm{CoMos}}$, as one could have expected. For $(\mathrm{Co} / \mathrm{Mo})_{\mathrm{CoMoS}}=0.2$, all crystallites have fully decorated S-edges (Fig. 16). For $(\mathrm{Co} / \mathrm{Mo})_{\mathrm{CoMoS}}>0.2$, Co also decorates M-edges (Fig. 17) as explained by in $[8,9]$; the number of mixed sites per

\section{TABLE 3}

Characteristics of various geometric models corresponding to an average length of $3.2 \mathrm{~nm}\left(n_{M}\right.$ (respectively $\left.n_{S}\right)$ is the number of atoms on the M-edge (respectively S-edge), $X_{M}$ is the proportion of M-edge)

\begin{tabular}{c|c|c|c|c|c}
\hline$n_{M}$ & $n_{S}$ & $L(\AA)$ & $X_{M}=n_{M} /\left(n_{M}+n_{S}\right)$ & $\begin{array}{c}\text { Highest number of mixed sites } \\
\text { per crystallite }\end{array}$ & $\begin{array}{c}\text { Geometrical (Ni/Mo) } \\
\text { corresponding to the highest number } \\
\text { of mixed sites per crystallite }\end{array}$ \\
\hline 5 & 4 & 29 & $55 \%$ & 12 & $0.15-0.20$ \\
6 & 3 & 29 & $66 \%$ & 12 & $0.20-0.25$ \\
6 & $\mathbf{4}$ & 35 & $\mathbf{6 0 \%}$ & 15 & 0.20 \\
6 & 5 & 32 & $50 \%$ & 15 & 0.20 \\
5 & 5 & & & \\
\end{tabular}

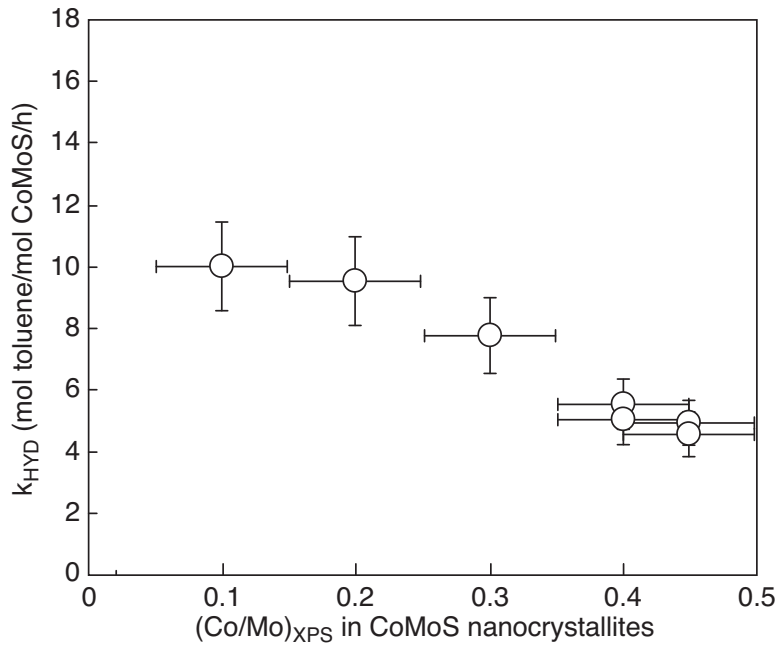

Figure 10

Toluene-hydrogenation activity normalized per mol of Co in $\mathrm{CoMoS}$ as a function of the $\mathrm{Co} / \mathrm{Mo}$ atomic ratio in the CoMoS nanocrystallites as quantified by XPS (after [8]).

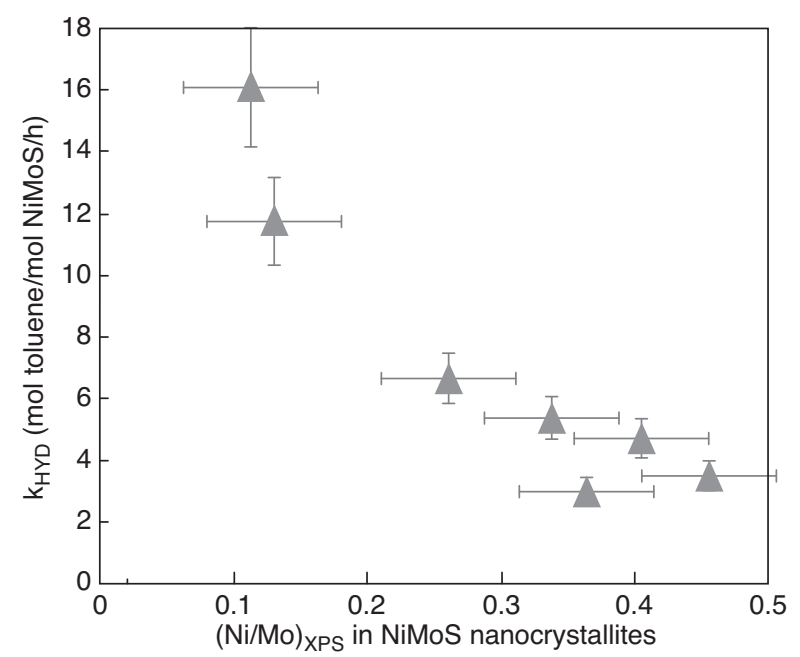

Figure 11

Toluene-hydrogenation activity normalized per mol of $\mathrm{Ni}$ in $\mathrm{NiMoS}$ as a function of the Ni/Mo atomic ratio in the NiMoS nanocrystallites as quantified by XPS. 


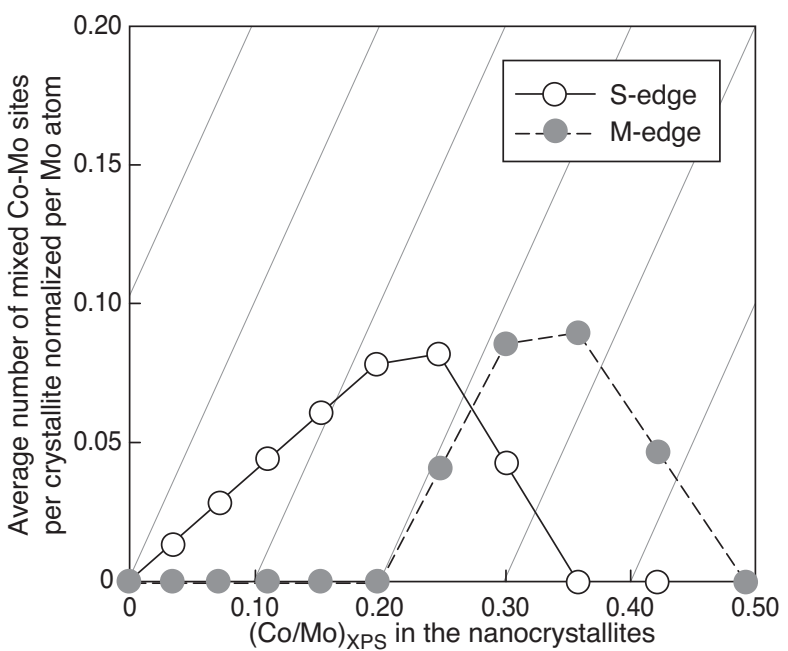

Figure 12

Average number of M-edge and S-edge mixed Co-Mo sites per crystallite normalized per molybdenum atom in the nanocrystallites as a function of the cobalt-to-molybdenum atomic ratio in the CoMoS nanocrystallites $\left(n_{M}=n_{S}=5\right)$.

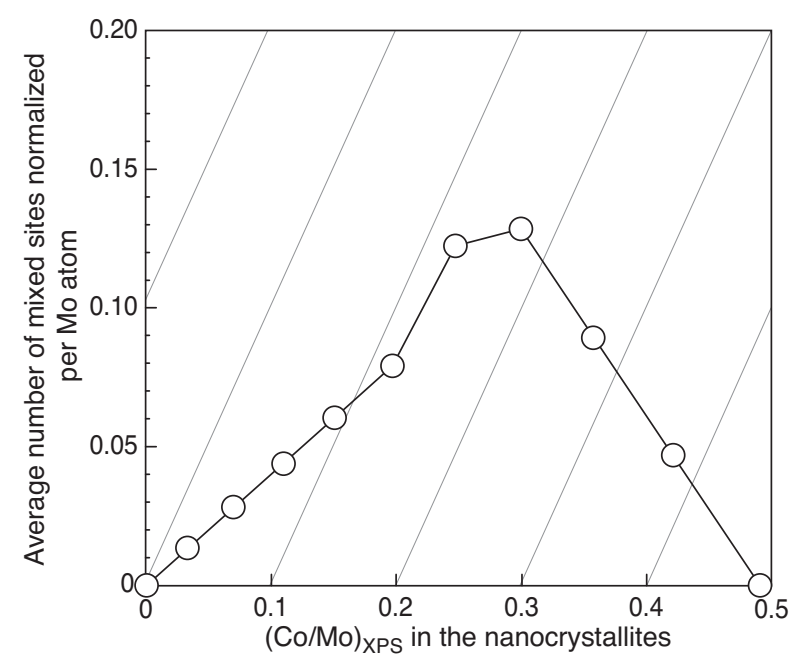

Figure 14

Average number of total mixed Co-Mo sites per crystallite normalized per molybdenum atom in the nanocrystallites as a function of the cobalt-to-molybdenum atomic ratio in the CoMoS nanocrystallites $\left(n_{M}=n_{S}=5\right)$.

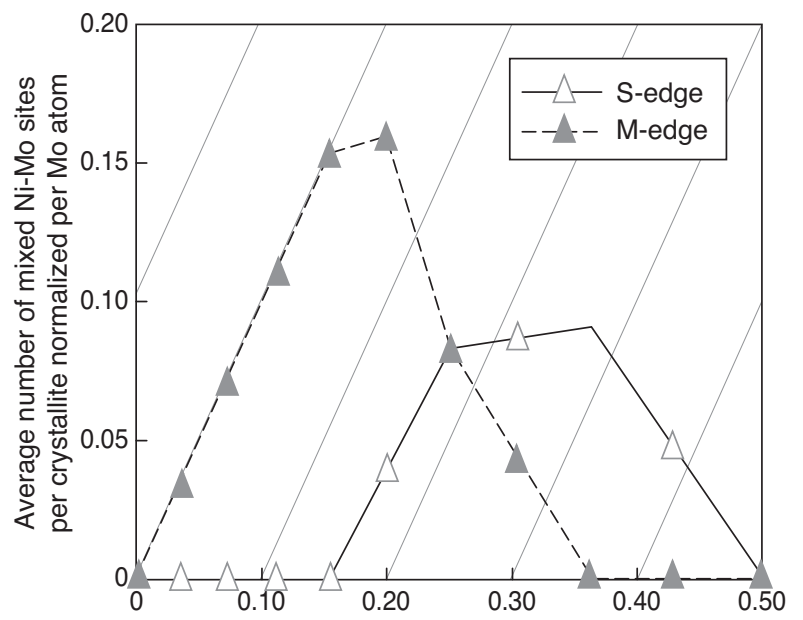

Figure 13

Average number of M-edge and S-edge mixed Ni-Mo sites par crystallite normalized per molybdenum atom in the nanocrystallites as a function of the nickel-to-molybdenum atomic ratio in the NiMoS nanocrystallites $\left(n_{M}=6, n_{S}=4\right)$

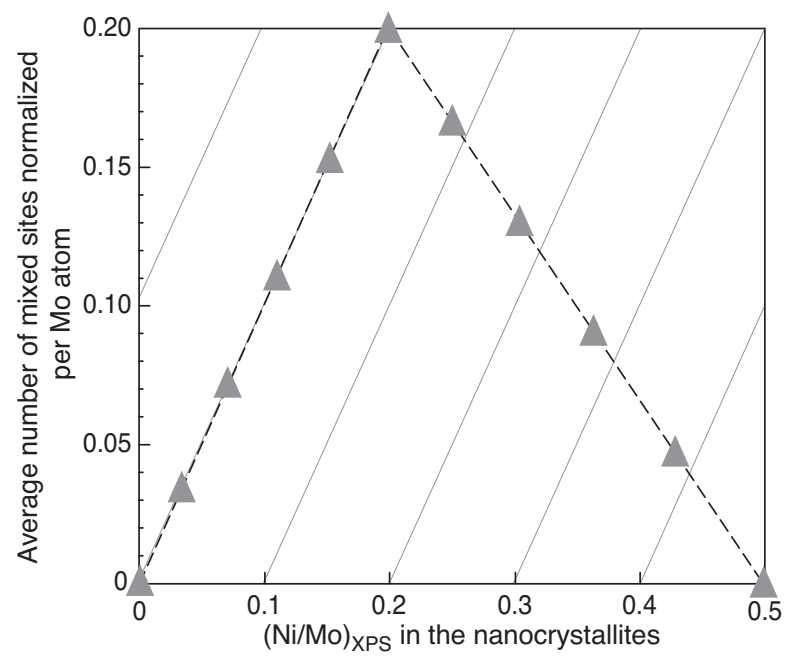

Figure 15

Average number of total mixed Ni-Mo sites per crystallite normalized per molybdenum atom in the nanocrystallites as a function of the nickel-to-molybdenum atomic ratio in the NiMoS nanocrystallites $\left(n_{M}=6, n_{S}=4\right)$. crystallite and per molybdenum atom is maximum for $(\mathrm{Co} / \mathrm{Mo})_{\mathrm{XPS}}=0.25-0.3$ (Fig. 14 and 18). However, since it is not as high as the number of Co in CoMoS phase, there is a small decrease of the activity normalized per Co atom in CoMoS phase compared to smaller values of $(\mathrm{Co} / \mathrm{Mo})_{\mathrm{XPS}}$. For $(\mathrm{Co} / \mathrm{Mo})_{\mathrm{XPS}}>0.3$, as may be seen in Figure 14 , the number of mixed sites per crystallites and per molybdenum atom decreases as well. Therefore, the decrease observed in activity is much more pronounced (Fig. 10) until a fully decorated crystallite has been reached.
By using a slightly deformed hexagonal as found by DFT simulation $\left(n_{M}=6\right.$ and $\left.n_{S}=4\right)$, the average numbers of mixed Ni-Mo sites per crystallite are plotted in Figures 13 and 15. Regarding NiMo catalysts, a first region exists for $(\mathrm{Ni} / \mathrm{Mo})_{\mathrm{NiMoS}}<0.15$ where the activity is much higher than that obtained with their CoMo counterparts; this is due to the fact that all the nickel decorating the NiMoS phase generates preferentially a Ni-Mo mixed site (Fig. 13). On top of that, one may notice that in this region, the mixed sites present on the NiMo catalyst are M-edge sites (Fig. 18), whereas 


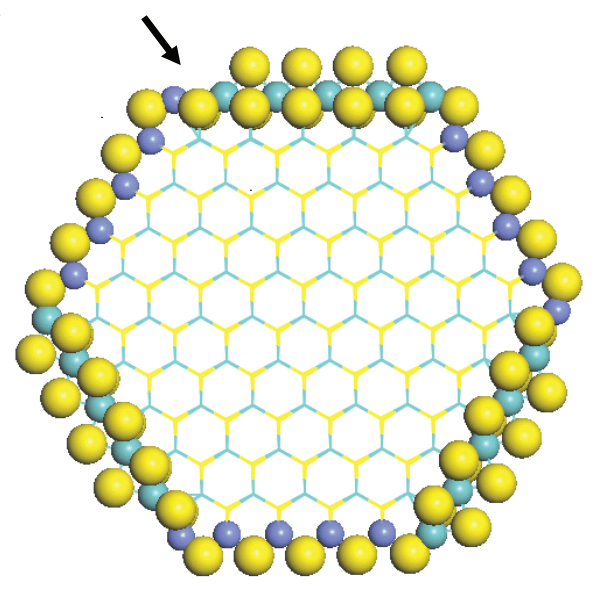

Figure 16

CoMoS crystallite with the fully-decorated S-edge with $n_{M}=n_{S}=5$ and $(\mathrm{Co} / \mathrm{Mo})_{\mathrm{CoMoS}}=0.20$. Mixed sites on the corners are indicated by the arrow.

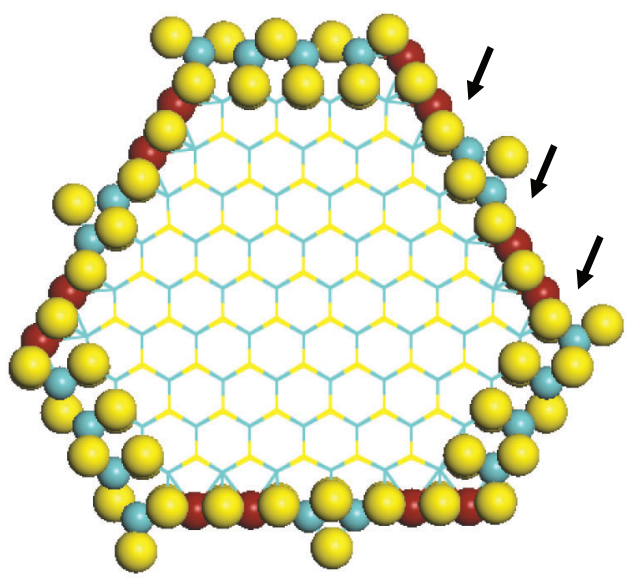

Figure 18

NiMoS crystallite with the M-edge partially decorated $\left(n_{M}=6, n_{S}=4\right)$ and $(\mathrm{Ni} / \mathrm{Mo})_{\mathrm{NiMoS}}=0.15$. Mixed sites on the M-edge are indicated by arrows.

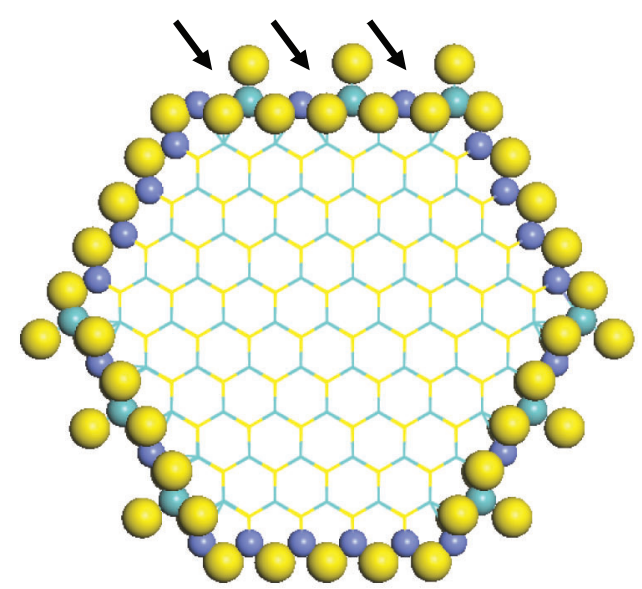

Figure 17

CoMoS crystallite with $n_{M}=n_{S}=5$ and $(\mathrm{Co} / \mathrm{Mo})_{\mathrm{CoMoS}}=0.30$. Mixed sites located on the M-edge are indicated by arrows.

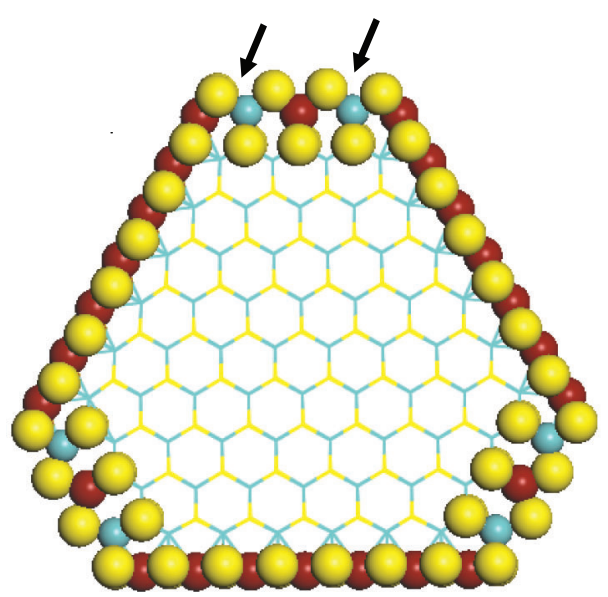

Figure 19

NiMoS crystallite with the M-edge fully decorated and the S-edge partially decorated $\left(n_{M}=6, n_{S}=4\right)$ and $(\mathrm{Ni} / \mathrm{Mo})_{\mathrm{NiMoS}}=0.36$. Mixed sites on the S-edge indicated by arrows. those present on the CoMo are only S-edge sites. This confirms DFT modeling results on the importance of the presence of M-edge sites for hydrogenation reactions. For $(\mathrm{Ni} / \mathrm{Mo})_{\mathrm{NiMoS}}>0.2$, a second region is obtained, which is quite similar as the one obtained previously for CoMo catalysts for $(\mathrm{Co} / \mathrm{Mo})_{\mathrm{XPS}}>0.3$ except that the activity is slightly higher for CoMo catalysts. This may also be rationalized if one considers the evolution of the number of mixed promoter-molybdenum sites per molybdenum atom as a function of the decoration ratio for both catalysts. Indeed, for
$(\mathrm{Co} / \mathrm{Mo})_{\mathrm{XPS}}>0.35$ the CoMo catalysts only exhibits M-edge mixed sites (Fig. 12), whereas for (Ni/Mo) XPS $>0.35$ the NiMo catalyst exhibits only S-edge mixed sites (Fig. 13, 19).

For non promoted $\mathrm{MoS}_{2}$ nano-crystallites deposited on gold support, STM experiments [27] have shown that hydrogenation of the aromatic ring of thiophene also occurs at the so-called "brim sites" under the specific STM conditions, corresponding to very low number of Coordinatively Unsaturated Sites (CUS) at the edges. However, it was also shown by DFT calculations that the more numerous 
Coordinatively Unsaturated Sites (CUS) present at the M-edge of $\mathrm{Co}(\mathrm{Ni}) \mathrm{MoS}$ crystallite in HDS conditions promote the adsorption energy of various reactant compounds [10, 11], including toluene molecules [9] and even polyaromatic coumpounds [18]. Hence, one predominant effect distinguishing the catalytic behavior of $\mathrm{MoS}_{2}, \mathrm{CoMoS}$ and NiMoS active phases in the hydrogenation of aromatic compounds is expected to be controlled by the number and nature of promoter present at the M-edge. Moreover, earlier DFT results have shown that the presence of $\mathrm{Co}$ and $\mathrm{Ni}$ at the edges directly modifies the sulfur-metal bond energy at the edge [28]. In particular, the sulfur-metal bond energy at the M-edge decreases with the increase of the $\mathrm{Co}$ and $\mathrm{Ni}$ content on this edge. The stronger sulfur-metal bond energy (S-Mo) is obtained for the non-promoted active phase and the weaker (S-Co) or (S-Ni) for the M-edge with $100 \%$ Co or Ni. Mixed $\mathrm{Co}(\mathrm{Ni})-\mathrm{Mo}$ sites present at the M-edge exhibit intermediate sulfur-metal bond energy values comprised between non-promoted Mo-site and pure Co site. Recent microkinetic investigations of the toluene hydrogenation on various transition metal sulfide catalysts have shown that a volcano curve correlates well the intrinsic catalytic activities with their sulfur-metal bond energies [29]. As a consequence, intermediate sulfur-metal bond energies of mixed $\mathrm{Co}(\mathrm{Ni})-\mathrm{Mo}$ sites provide the optimal surface concentrations for the reactive species involved in the kinetically limiting step of toluene hydrogenation:-SH groups and toluene. A full saturation of the M-edge by $\mathrm{Co}$ or Ni implies a too weak concentration of these reactive species inducing a loss of the toluene-hydrogenation turnover frequency. In contrast, the mixed $\mathrm{Co}(\mathrm{Ni})-\mathrm{Mo}$ sites at the M-edge provides the best species distribution at the edges required for toluene hydrogenation.

\section{CONCLUSIONS}

This paper has investigated the properties of the NiMoS active phase combining TEM, XPS and DFT calculations and compared them with those obtained for the CoMoS phase obtained in a previous study $[8,9]$. TEM has shown that the mean particle sizes are close to $3.2 \mathrm{~nm}$ and do not depend on the Ni content. XPS quantification of the Mo species has shown that $70 \%$ of the Mo species are present in the $\mathrm{MoS}_{2}$ phase. The decomposition of the XPS spectrum has enabled the quantification of the NiMoS phase and the determination of the decoration ratios of the NiMoS nanocrystallites. With the help of DFT calculations, an atomistic morphological model has been proposed and confronted to catalytic results obtained in toluene hydrogenation. These experimental and theoretical results emphasize the role of M-edge mixed sites for aromatic hydrogenation reactions. According to further recent theoretical investigations $[21,30]$, this concept can probably be extended to hydrogenation of olefins, which provides new guidelines for molecular design of future and ever more active catalysts.

\section{ACKNOWLEDGMENTS}

The authors wish to thank S. Sahal for catalysts preparation and testing and P. Lecour for XPS analyses.

\section{REFERENCES}

1 Breysse M., Bennet B.A., Chadwick D., Vrinat M. (1981) B. Soc. Chim. Belg. 90, 1271.

2 Alstrup I., Chorkendorff I., Candia R., Clausen B.S., Topsoe H. (1982) A combined X-Ray photoelectron and Mössbauer emission spectroscopy study of the state of cobalt in sulfided, supported, and unsupported Co-Mo catalysts, J. Catal. 77, 397.

3 Gandubert A.D., Legens C., Guillaume D., Rebours S., Payen E. (2006) X-ray photoelectron spectroscopy surface quantification of sulfided CoMoP catalysts. Relation between activity and promoted sites, Surf. Interface Anal. 28, 206.

4 Coulier L., de Beer V.H.J., van Veen J.A.R., Niemantsverdriet J.W. (2000) On the formation of cobaltmolybdenum sulfides in silica-supported hydrotreating model catalysts, Top. Catal. 13, 99.

5 Garreau F.B., Toulhoat H., Kasztelan S., Paulus R. (1986) Low temperature synthesis of mixed NiMo sulfides: structural, textural and catalytic properties, Polyhedron 5, 211.

6 Houssenbay S., Kasztelan S., Toulhoat H., Bonnelle J.P., Grimblot J. (1989) Nature of the different nickel species in sulfided bulk and alumina-supported nickel-molybdenum hydrotreating catalysts, J. Phys. Chem. 93, 7176.

7 Coulier L., de Beer V.H.J., van Veen J.A.R., Niemantsverdriet J.W. (2001) Correlation between Hydrodesulfurization Activity and Order of $\mathrm{Ni}$ and Mo Sulfidation in Planar Silica-Supported NiMo Catalysts: The Influence of Chelating Agents, J. Catal. 197, 26.

8 Gandubert A.D., Legens C., Guillaume D., Rebours S., Payen E. (2007) X-ray photoelectron spectroscopy surface quantification of sulfided CoMoP catalysts - Relation between activity and promoted sites, Oil Gas Sci. Technol.Rev. IFP 62, 79.

9 Gandubert A.D., Krebs E., Legens C., Costa D., Guillaume D., Raybaud P. (2008) Optimal promoter edge decoration of CoMoS catalysts: A combined theoretical and experimental study, Catal. Today 130, 149.

10 Raybaud P. (2007) Understanding and predicting improved sulfide catalysts: Insights from first principles modeling, Appl. Catal. A: Gen. 322, 76.

11 Paul J.-F., Cristol S., Payen E. (2008) Computational studies of (mixed) sulfide hydrotreating catalysts, Catal. Today $\mathbf{1 3 0}$, 139.

12 Kasztelan S., Toulhoat H., Grimblot J., Bonnelle J.P. (1984) A geometrical model of hydrotreating catalysts. Prediction of catalytic activity variations with composition, Appl. Catal. A: Gen. 13, 127.

13 Schweiger H., Raybaud P., Kresse G., Toulhoat H. (2002) Shape and Edge Sites Modifications of $\mathrm{MoS}_{2}$ Catalytic Nanoparticles Induced by Working Conditions: A Theoretical Study, J. Catal. 207, 76. 
14 Schweiger H., Raybaud P., Toulhoat H. (2002) Promoter sensitive shapes of $\mathrm{Co}(\mathrm{Ni}) \mathrm{MoS}$ nanocatalysts in sulfo-reductive conditions, J. Catal. 212, 33.

15 Byskov L.S., Hammer B., Nørskov J.K., Clausen B.S., Topsøe H. (1997) Sulfur bonding in MoS2 and Co-Mo-S structures, Catal. Lett. 47, 177.

16 Lauritsen J.V., Nyberg M., Nørskov J.K., Clausen B.S., Topsøe H., Lægsgaard E., Besenbacher F. (2004) Hydrodesulfurization reaction pathways on $\mathrm{MoS}_{2}$ nanoclusters revealed by scanning tunneling microscopy, J. Catal. 224, 94.

17 Griboval A., Blanchard P., Payen E., Fournier M., Dubois J.L. (1998) Alumina supported HDS catalysts prepared by impregnation with new heteropolycompounds. Comparison with catalysts prepared by conventional Co-Mo-P coimpregnation, Catal. Today 45, 277.

18 Guichard B., Roy-Auberger M., Devers E., Legens C., Raybaud P. (2008) Aging of $\mathrm{Co}(\mathrm{Ni}) \mathrm{MoP} / \mathrm{Al}_{2} \mathrm{O}_{3}$ catalysts in working state, Catal. Today 130, 97.

19 Wang X., Saleh R.Y., Ozkan U.S. (2005) Effect of S-compounds and $\mathrm{CO}$ on hydrogenation of aldehydes over reduced and sulfided $\mathrm{Ni}-\mathrm{Mo} / \mathrm{A} 12 \mathrm{O} 3$ catalysts, Appl. Catal. A: Gen. 286, 111.

20 Escobar J., Barrera M.C., Toledo J.A., Cortés-Jácome M.A., Angeles-Chávez C., Núñez S., Santes V., Gómez E., Díaz L. Romero E., Pacheco J.G. (2009) Effect of ethyleneglycol addition on the properties of P-doped NiMo/Al2O3 HDS catalysts: Part I. Materials preparation and characterization, Appl. Catal. B: Environ. 88, 564.

21 Krebs E., Daudin A., Raybaud P. (2009) A DFT Study of CoMoS and NiMoS Catalysts: from nano-crystallite morphology to selective hydrodesulfurization, Oil Gas Sci. Technol. - Rev. IFP (this issue), DOI: 10.2516/ogst/2009004.

22 Krebs E., Silvi B., Raybaud P. (2007) Mixed sites and promoter segregation: A DFT study of the manifestation of Le Chatelier's principle for the $\mathrm{Co}(\mathrm{Ni}) \mathrm{MoS}$ active phase in reaction conditions, Catal. Today 130, 160.
23 Kohn W., Sham L.J. (1965) Self-Consistent Equations Including Exchange and Correlation Effects, Phys. Rev. A 140, 1133.

24 Perdew J.P., Wang Y. (1992) Accurate and simple analytic representation of the electron-gas correlation energy, Phys. Rev. B 45, 13244 .

25 Kresse G., Furthmüller J. (1996) Efficiency of ab-initio total energy calculations for metals and semiconductors using a planewave basis set, Comput. Mater. Sci. 6, 15.

26 Lauritsen J.V., Kibsgaard J., Olesen G.H., Moses P.G., Hinnemann B., Helveg S., Norskøv J.K., Clausen B.S., Topsøe H., Lægsgaard E., Besenbacher F. (2007) Location and coordination of promoter atoms in $\mathrm{Co}-$ and $\mathrm{Ni}$-promoted $\mathrm{MoS}_{2}$-based hydrotreating catalysts, J. Catal. 249, 220.

27 Lauritsen J.V., Nyberg M., Vang R.T., Bollinger M.V., Clausen B.S., Topsoe H., Jacobsen K.W., Laegsgaard E., Norskov J.K., Besenbacher F. (2003) Chemistry of onedimensional metallic edge states in $\mathrm{MoS}_{2}$ nanoclusters, Nanotechnology 14, 385.

28 Raybaud P., Hafner J., Kresse G., Kasztelan S., Toulhoat H. (2000) Structure, Energetics, and Electronic Properties of the Surface of a Promoted MoS2 Catalyst: An ab Initio Local Density Functional Study, J. Catal. 190, 128.

29 Guernalec N., Geantet C., Raybaud P., Cseri T., Aouine M., Vrinat M. (2006) Dual Effect of $\mathrm{H}_{2} \mathrm{~S}$ on Volcano Curves in Hydrotreating Sulfide Catalysis, Oil Gas Sci. Technol. - Rev. IFP 61, 515 .

30 Krebs E., Silvi B., Daudin A., Raybaud P. (2008) A DFT study of the origin of the $\mathrm{HDS} / \mathrm{HydO}$ selectivity on $\mathrm{Co}(\mathrm{Ni}) \mathrm{MoS}$ active phases, J. Catal. 260, 276.

Final manuscript received in June 2009 Published online in September 2009

Copyright $@ 2009$ Institut français du pétrole

Permission to make digital or hard copies of part or all of this work for personal or classroom use is granted without fee provided that copies are not made or distributed for profit or commercial advantage and that copies bear this notice and the full citation on the first page. Copyrights for components of this work owned by others than IFP must be honored. Abstracting with credit is permitted. To copy otherwise, to republish, to post on servers, or to redistribute to lists, requires prior specific permission and/or a fee: Request permission from Documentation, Institut français du pétrole, fax. +33147527078 , or revueogst@ifp.fr. 